\section{If I Understood You, Would I Have This Look on My Face? My Adventures in the Art and Science of Relating and Communicating}

\section{Alan Alda}

New York, Random House, 2017, 197 pp., \$28, hardcover

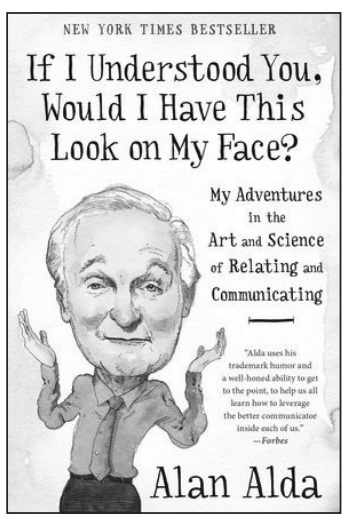

Many of us know Alan Alda best from his comedic work on the TV show $M * A * S * H$. I was surprised and impressed, however, to learn about his longstanding passion for science and scientific communication. In addition to his work in TV and film, he previously hosted Scientific American Frontiers, a program dedicated to sharing scientific discoveries and new technologies with the public, and also founded the Stonybrook University Alan Alda Center for Communicating Science. In If I Understood You..., he uses his experiences as both an actor and an improvisation teacher to illustrate the challenges and rewards of effective communication-lessons that are particularly relevant to the medical community.

Alda introduces his book with a personal experience in which he is a patient. During multiple interactions, his dentist does all of the things he should not do: use medical jargon, place Alda in a literally vulnerable position with "the sharp end of the blade inches from [his] face" (p xiv), appear impatient, and act defensive and unapologetic when questioned about the undesired results of a procedure. Alda states, "I wasn't looking for friendship that day, but at least I wanted the feeling that I was actually being seen by him." Rather, he felt like he was "something on his checklist" ( $p$ xvi). My visceral negative reaction to Alda's experience prompted me to consider how many times we as physicians have made patients feel uncomfortable, frustrated, or invalidated by not adequately communicating with them or hearing their concerns. This example was clearly egregious, but how many times do we miss subtler opportunities to connect with one another, and, more specifically, with our patients? Alda convincingly contends that these interactions could be significantly improved with the addition of empathy and authentic engagement.

The first section of the book, entitled "Relating is Everything," begins with Alda's first experience interviewing a scientist on Scientific American Frontiers, which went poorly. His reflections on this interaction led him to explore meaningful communication through improvisation. Through a series of improv exercises, he demonstrates the power of synchrony, the value of responsive and contagious listening, and the role of social connection in improving communication. In the second section, "Getting Better at Reading Others," Alda examines the cultivation and expression of empathy. Using a combination of vignettes, training exercises, and scientific studies, he illustrates how observing others' emotions and appreciating their stories fosters genuine connection and empathy.

Alda himself is a direct and skillful communicator, qualities that enhance his credibility on the subject. He employs an informal, conversational tone, and the content is rich, stemming from years of personal experience and collaboration with experts in scientific communication. He reminds us that "good communication is the responsibility of the person delivering the information, not the person receiving it" ( $p$ 73). I particularly enjoyed the medically relevant examples, including work by Helen Reiss, a psychiatrist, and Evonne Kaplan-Liss, a journalist turned pediatrician, as well as the exercise "Reading the Mind in the Eyes," which assesses one's ability to read others' emotions by only looking at their eyes. Though thought-provoking, the book included an excess of examples to illustrate the primary purpose. While some of the examples build on each other, individual chapters can be read separately to take away the salient points.

In this book, the parallels between scientific communication and physician-patient interactions are readily apparent. Alda refers to multiple studies that show the benefits of 
effective communication skills, including better health outcomes as well as improved satisfaction for both patients and clinicians. Entering a patient room "only with curiosity and [one's] own natural ignorance" and welcoming his/her story promotes relationship building that can be long-lasting ( $p$ 11). Alda provides concrete examples, including a variety of improv exercises, which clinicians may employ to practice effective communication and nurture empathy. This book reiterates the importance of teaching and evaluating communication skills as part of resident training and continuing to reassess them over time. It is a worthwhile read for all, especially family physicians who hope to build lasting, meaningful relationships with their patients.

doi: 10.22454/FamMed.2018.446419

Erin Peck, MD, PhD

University of Rochester Medical Center Rochester, NY

\section{Healthcare Choices: 5 Steps to Getting the Medical Care You Want and Need}

Archelle Georgiou

Lanham, MD, Rowman \& Littlefield, 2017, 193 pp., \$35, hardcover

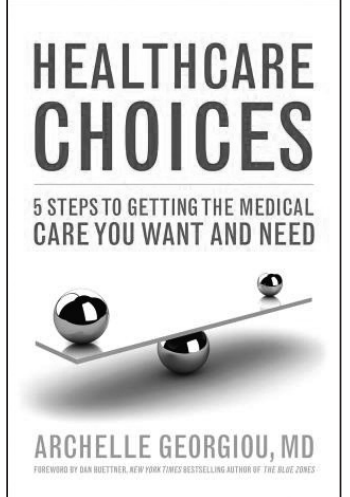

Archelle Georgiou, MD's book is outstanding. Her background as a former chief medical officer for United Healthcare and her mission to educate consumers on health care resulted in the CARES model, which is the framework for Healthcare Choices: 5 Steps to Getting the Medical Care You Want and Need, her first book. CARES translates to: Understand your Condition, know your Alternatives, Respect your preferences, Evaluate your options, and Start taking action. She emphasizes that health care consumers cannot be passive bystanders in their own care - the health care industry is geared to say "no." Individuals must be prepared to be actively involved in their own care or the care of individuals they are responsible for.

From a lay educator perspective, Dr Georgiou is the on-camera medical expert for
KSTP-TV in St Paul, Minnesota, and has an active Facebook page where she answers real-life health-related questions. She uses those roles throughout the book to frame actual consumer questions with the appropriate actions to take using the CARES model. For every chapter and every issue discussed, she hammers home her point using the model to walk consumers through a step-by-step process, making it very easy to follow the logic and rationale for options in simple language. Dr Georgiou's role as an industry advisor for the Medical Industry Leadership Institute at the University of Minnesota's Carlson School of Management, where she serves as an executive in residence, gives her credibility with clinicians and university faculty.

The book covers a wide range of topics and practical tips, ranging from how to address your doctor in conversations that establish a level playing field, to recommendations for the best online layperson medical resource for many conditions (mayoclinic.org). A key point is the importance of being objective and learning evidence-based facts instead of allowing decisions to be colored by perception. For example, when discussing options for breast cancer treatment, a patient might choose an option that worked for a friend of theirs because it sounds familiar and makes them feel comfortable, instead of an unfamiliar option that may be a better choice for their individual health condition.

Chapter 6, "Aging With Control" is of particular interest. Utilizing the CARES model, she provides information about dementia and endof-life care as an example of understanding one's condition. This includes an interesting discussion of the effects of ageism, beginning with how older adults allow themselves to be negatively addressed, effectively making them unable to express their preferences or have their preferences respected. The passage on understanding the alternatives (p 97) will be an eye opener for many older adults who believe "my family will take care of me" or "I can rely on Medicare or Medicaid for help." A discussion of residential options, costs, and other pros and cons provides an opening for caregivers and clinicians to initiate conversations with older adults about living arrangements.

Also interesting is chapter 7, "Selecting Your Healthcare A-Team," which includes a tip for phrasing a request for a second opinion as a desire to obtain a consultation. Consultations are perceived positively by clinicians as consumers seeking information and options. 
Second opinions are often perceived as unhappy patients possibly seeking to place blame. The key take-home point for this chapter is the importance of patients maintaining their own copies of medical records instead of relying on doctors or organizations sharing information. "The fastest, cheapest, and most efficient way to assure that every doctor has access to all your records is to give them a comprehensive set yourself" (p 132).

Chapter 8, "Powershopping for Health Insurance," drives home the importance of health care navigators who can help consumers choose the right insurance plan for their needs and budgets. This book was written before the current administration began dismantling Obamacare support services, when health care navigators were available to assist with decision making. For those who have employerprovided insurance with a choice of two plans, or for those who need to purchase their own plan on a health insurance exchange, it can be equally confusing and frustrating. Dr Georgiou cites a 2013 study finding only one in seven Americans understands the basic components of a health insurance plan. ${ }^{1}$

Chapter 10 provides a summary of CARES models for a quick reference, but each chapter is a wealth of information, easily read and understood. The framework and tools are practical and easily implemented, but need to be taught to and practiced by individual health care consumers.

As a medical professional with 39 years of experience dealing with multiple family medical issues, I approached this review with a healthy dose of skepticism and doubt that any book intended for the public could actually help navigate the mess that our health care system has become. I was wrong. This book is an easy read for consumers and clinicians, offers excellent advice, and would make a wonderful textbook for an introductory course on effective health care decision making for a wide variety of audiences.

doi: 10.22454/FamMed.2018.401560

Julie M. Stausmire, MSN, APRN.CNS

Mercy Health St Vincent Medical Center Toledo, $\mathrm{OH}$

\section{References}

1. Loewenstein G, Friedman JY, McGill B, et al. Consumers' misunderstanding of health insurance. J Health Econ. 2013;32(5):850-862

\section{Two Titles for the Family Medicine Board Review}

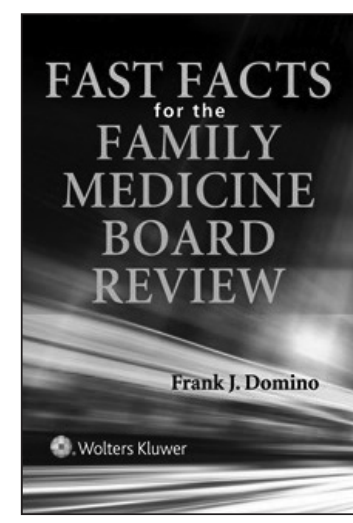

\section{Fast Facts for the Family Medicine Board Review}

Frank J. Domino

Philadelphia: Wolters Kluwer, 2017, 219 pp., \$54.99, paperback

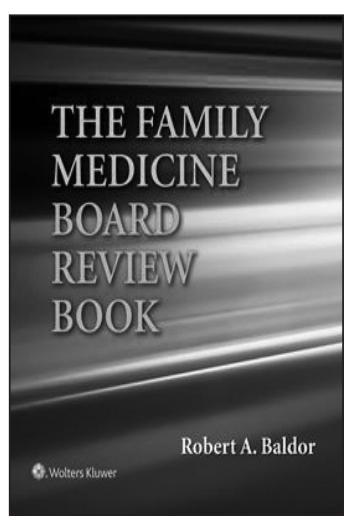

\section{The Family Medicine Board Review Book}

Robert A. Baldor

Philadelphia, Wolters Kluwer, 2018, 351 pp., \$84.99, paperback

Passing the family medicine boards is a necessity that every graduating resident, as well as the rest of us in family medicine, faces every 7 to 10 years. I should know-I just took them for the third time in my career. For most of us, the boards are not getting any easier. However, using these two review books as a 1-2 tandem can make the task much more manageable. In his book, Fast Facts for the Family Medicine Board Review, Frank Domino offers approximately 1,300 factoids organized smartly into the same categories that the test covers: pediatrics, internal medicine, obstetrics and gynecology, psychiatry, surgery/emergency care, and general facts. Each page has a short question on the left-hand side and a short answer on the right-hand side. The physical setup of the page allows the reader to cover the answer with a hand or a slip of paper and test his or her knowledge question-by-question and page-by-page. It is easy enough to make marks in the book to return to unknown facts at a future sitting. The book occasionally asks the same content using a different question, which at first seems annoying, yet helps solidify important concepts through repetition.

The Robert Baldor book, The Family Medicine Board Review Book, takes a different 
approach, but one that works well when combined with Domino's book. The questions are in chapters organized into the same categories as Domino's book. Baldor has created approximately 1,800 multiple-choice questions in American Board of Family Medicine (ABFM) format to teach the reader high-yield facts. With this format, the reader is learning in a style that is very practical for the test. The questions are generally well written and there is a short answer section that explains the why behind the answer with a reference to a well known resource (eg, article from American Family Physician). This book also benefits from having a photo section that includes EKGs, radiographs, and skin lesions. While there are only a few images on the actual boards, this brief review of images is fun and increases the reader's confidence with such questions. Lastly, Baldor has a must-know fact on every other page in a highlighted box.

Both books have excellent introductions that are worth reading. The authors offer calming words about the test, but more importantly explain how the test is organized and some test taking strategies. Baldor goes into more detail about common error types that test takers make; this metacognitive insight will help readers as they review practice questions to think about not only what they got wrong but why they got the questions wrong, and how to get a similar question right in the future. Baldor's book has a study grid in the back where one can record progress and what type of errors they are making. He also explains the ABFM Board Certification process and the exam itself. Both books have detailed indexes so it is easy to find an answer about a specific topic.

A unique feature of both books is that they come with free downloadable access of the ebook version onto multiple devices (at the same time) including your computer, laptop, tablet, and smartphone. For those who need to squeeze in studying during commutes or free time, this convenience is very helpful.

The cost of these books is a small price to pay for senior residents and practicing physicians to prepare for the boards. Many online or in-person courses can cost 10 to 20 times more. The books cover a great deal of material. Of course, they do not review everything that is on the exam; however, they strategically focus on the bread and butter topics that test designers like to cover. While I did find a few minor errors in the book, both authors encourage letting them know so that they can make corrections for future editions. These books make what could be a painful process much less painful. In fact, Domino writes in his introduction, "Smile! You now have all of the skills and knowledge to succeed at the [ABFM] certification examination." Maybe not all of the skills and knowledge, but you will be well on your way, and the authors even offer advice about what to do when you have no idea about a question. After using these resources, having no knowledge for a question will be a rare event. I know - the books helped me pass my test!

doi: 10.22454/FamMed.2018.654986

\section{Hugh Silk, MD, MPH}

University of Massachusetts Medical School Department of Family Medicine and Community Health

Worcester, MA

Reviewers interested in writing reviews for publication should contact Book and Media Reviews Editor William E. Cayley, Jr, MD, at bcayley@yahoo.com.

Publishers who wish to submit books for possible inclusion in Family Medicine's book reviews section should send texts to Sam Grammer, Society of Teachers of Family Medicine, 11400 Tomahawk Creek Parkway, Suite 240, Leawood, KS 66211. fmjournal@stfm.org 